\title{
Red-Eared Slider Turtles Lack Response to Immunization with Keyhole Limpet Hemocyanin but Have High Levels of Natural Antibodies
}

\author{
Laura M. Zimmerman, Rachel M. Bowden, and Laura A. Vogel \\ School of Biological Sciences, Illinois State University, Campus Box 4120, Normal, IL 61790-4120, USA \\ Correspondence should be addressed to Laura M. Zimmerman; Imzimme@ilstu.edu
}

Received 24 October 2013; Accepted 28 November 2013

Academic Editors: D. V. Andrade, B. Crother, and C.-F. Weng

Copyright (C) 2013 Laura M. Zimmerman et al. This is an open access article distributed under the Creative Commons Attribution License, which permits unrestricted use, distribution, and reproduction in any medium, provided the original work is properly cited.

\begin{abstract}
While the specific humoral response of reptiles is slow and does not typically increase in titer or binding affinity upon secondary immunization, reptiles produce polyreactive natural antibodies (NAbs) that have low binding affinity and are produced in the absence of antigen stimulation. Given the poor specific response, NAbs may be an important protective resource in reptiles. In order to investigate the relative contributions of natural and specific antibodies, we immunized turtles with the novel antigen keyhole limpet hemocyanin (KLH). We did not detect an increase in antibody titers. However, preimmunization titers to KLH, as well as to a series of other novel antigens, were high in the turtles, indicating a strong NAb response. Interestingly, we found an age-associated increase in NAb titers in adults. Overall, our data suggest that reptiles may use NAbs as part of a strong innate immune response rather than relying on slower specific humoral responses.
\end{abstract}

\section{Introduction}

The vertebrate immune system is a complex network of cells and molecules that interact to protect the animal against constant attacks from pathogens. Upon initial contact with an antigen, the nonspecific innate branch of the immune system responds quickly to act as a first line of defense [1]. At this time there is also activation of the humoral branch, which involves the production of highly specific antibodies by $\mathrm{B}$ cells. Antibodies are important in protecting against pathogens because of their role in facilitating lysis of microorganisms, neutralizing toxins, and agglutinating microorganisms to improve phagocytosis [2].

Humoral responses are often studied by deliberately immunizing naïve animals with an antigen to which they have not been exposed previously (a novel antigen) and then examining the resulting antibody response. The kinetics of the humoral response to immunization is well studied in mammals and, to a lesser extent, in birds. When exposed to a novel antigen, a latent phase occurs in which $\mathrm{T}$ and $\mathrm{B}$ cells first make contact with the antigen and begin to proliferate and differentiate. In mammals, this latent period lasts around 1 to 2 weeks depending on such factors as type and dose of antigen used and immunization route. In birds, the latent period is around 3 to 5 days depending on the species [3]. After the latent period, antibody titers increase exponentially and peak at a steady state shortly thereafter. During this phase, IgM is the first antibody produced, which is then supplanted by IgG in mammals and IgY in birds [4]. After reaching peak titers, antibody production in mammals begins to decline and ceases within a few weeks. The antibody response in birds is more rapid, but of shorter duration than mammals, most likely due to the higher body temperatures of birds [4]. Upon a second exposure to the antigen, the latent period is shortened and antibody titers are increased in both birds and mammals [3]. In mammals, binding affinity of the antibody to the antigen is increased [5]; however, it is unclear if affinity maturation also occurs in birds [6]. Antigen-driven affinity maturation and memory cell generation are hallmarks of an adaptive immune response.

Reptiles have humoral immune responses as well but, in comparison to birds and mammals, much less is known about 
their response. Immunization studies on several species of reptiles have shown that, while antibodies can be detected after 1 week, peak antibody titers are often not reached until 6 to 8 weeks after the primary immunization [7]. The latent period is shortened after a secondary immunization, but there is often no increase in titer when compared to the primary response. There is also no evidence for an increase in binding affinity [7]. While this delay in the humoral response could be attributed to the fact that reptiles are ectotherms and have a more variable body temperature, Grey found that housing of painted turtles (Chrysemys picta) at a higher temperature did not change the kinetics of the response [8]. Therefore, the comparatively slow humoral immune response may not be a function of temperature alone.

Because the reptilian specific humoral response is much slower in comparison to the mammalian humoral response and often does not result in increased antibody titers upon a second immunization or increased binding affinity in response to exposure to an antigen, reptiles may rely upon another type of humoral response, the production of natural antibodies (NAbs). At present, little is known about NAbs in reptiles, but NAbs have been described in a number of taxonomic groups $[9,10]$, and clues to their function may come from studies in mammals. Produced mainly by a subset of B cells known as B-1 cells, NAbs are spontaneously secreted in the absence of antigen stimulation [11]. NAbs are encoded by germ line gene segments [12] and consist predominately of IgM, but IgG and IgA isotypes have also been detected [13]. Often self-reactive, NAbs are thought to play essential "housekeeping" roles in everything from Alzheimer's disease to atherosclerosis [14]. NAbs have low binding affinity and most NAbs are polyreactive to evolutionarily conserved components of pathogens [11] and thus also play an important role in the early defense against pathogens. They can trigger innate immunity by activating the complement cascade as well as facilitate adaptive immunity by targeting the antigen to the spleen to activate B cells [11]. Studies have shown that NAbs can reduce the severity of and increase survival against both viral and bacterial infections by limiting the spread of pathogens to vital organs while also improving antigen trapping in the secondary lymphoid organs $[15,16]$. Given the capacity of NAbs to provide recognition for a broad range of antigens as well as initiate a variety of immune responses, they may indeed be an integral component of the reptilian immune response.

Red-eared slider turtles (Trachemys scripta) live in habitats that likely expose them to a variety of antigens, are opportunistic omnivores that will readily eat carrion [17], and often show signs of injury but rarely exhibit signs of infection (pers. obs.). Yet, we know little about the immune responses of red-eared sliders, including how they might avoid serious infections given their many potential routes of exposure to pathogens. Previously, we found an increase with age in total immunoglobulins [18] and lipopolysaccharide- (LPS-) specific antibodies [19], further indicating that they may also utilize a natural antibody response. We demonstrated in vitro that B cells from red-eared sliders respond to stimulation with LPS by increasing both the number of antibody secreting cells and the amount of antibody secreted by each cell [19].
In order to investigate their humoral response in vivo, we immunized turtles from a natural population with a presumably novel antigen, keyhole limpet hemocyanin (KLH), and measured KLH-specific antibody levels and the avidity of the antibodies for KLH. KLH is a highly immunogenic protein antigen commonly used to induce specific antibodies in laboratory mammals. While affinity is a measure of how strong a single antibody binds to an antigen, avidity is the strength of the binding of a population of antibodies. Given previous data on the reptilian humoral response, we had initially predicted an increase in antibody titers to KLH upon immunization with a shortened latent period after a second injection and little to no change in avidity. However, we found that the turtles had significant levels of antibodies to KLH preimmunization and did not elevate titers or avidity after immunization. These results suggested that slider turtles may utilize a predominant NAb response. To further characterize the preexisting antibody reactivity, we investigated the ability of slider antibodies to bind to a whole suite of presumably novel antigens and determined if those titers varied across the active season or with age.

\section{Materials and Methods}

2.1. Immunization. In May 2012, sixteen female adult turtles were trapped at Banner Marsh State Fish and Wildlife Area, Fulton County, Illinois, and transported to Illinois State University. Only females were used due to the difficulty of trapping enough males at this time of year. In a previous study, we found no sex differences in the ability of slider leukocytes to produce antibodies in response to stimulation with LPS [19]. Because red-eared sliders grow throughout their lifetime [17], we measured plastron length to the nearest $\mathrm{mm}$ as a proxy for age $[20,21]$. Females used in this study ranged from 182 to $234 \mathrm{~mm}$. Turtles were housed in 100 gallon tanks held at an average water temperature of $27^{\circ} \mathrm{C} \pm 1.5^{\circ} \mathrm{C}$ with a natural light cycle. Basking platforms were provided in the tanks for the turtles. Water temperature was monitored daily and turtles were fed pelleted reptile food three times a week. A preimmunization blood sample was taken from the caudal vein using an EDTA-coated syringe to prevent clotting. Eight turtles were then immunized intraperitonealy with $100 \mu \mathrm{L}$ of a $1 \mathrm{mg} / \mathrm{mL}$ of keyhole limpet hemocyanin (KLH; Sigma) in PBS solution absorbed into $100 \mu \mathrm{L}$ of alum (Pierce Chemical) and eight other turtles were injected with $100 \mu \mathrm{L}$ PBS absorbed into $100 \mu \mathrm{L}$ of alum as a control. Turtles were bled every two weeks for a total of eight weeks. Turtles were then given a booster injection as before and bled every two weeks for six more weeks. For all blood samples collected, plasma was separated by centrifugation and stored at $-20^{\circ} \mathrm{C}$. After the last blood sample was collected, all turtles were returned to their site of capture. Plasma was tested for quantity using an ELISA and avidity of antibodies against KLH using a competitive ELISA.

2.2. Natural Antibodies. To further characterize the nature of the preimmunization antibody levels in the general population, we utilized stored plasma from nonimmunized turtles 
that had been captured previously. Adult male and female red-eared sliders were trapped periodically at Banner Marsh State Fish and Wildlife Area throughout the active season of May through September 2007. Male plastron length ranged from 111 to $220 \mathrm{~mm}$ and female plastron length ranged from 106 to $241 \mathrm{~mm}$. Blood samples were taken from each turtle from the caudal vein using an EDTA-coated syringe. Plasma was separated by centrifugation and stored at $-20^{\circ} \mathrm{C}$. Plasma from 20 males and 20 females was tested for antibodies against tetanus toxoid (Fort Dodge), KLH, and hen egg white lysozyme (HEWL; Sigma) using an ELISA.

Plasma was collected from 25 hatchling T. scripta in March 2008 to assess whether NAbs are present at hatch, potentially as a result of maternal transfer to offspring. Blood was collected from the postcranial sinus using an EDTAcoated syringe. Plasma was separated by centrifugation and stored at $-20^{\circ} \mathrm{C}$ until assayed by ELISA. Due to the limited amount of hatchling plasma, it was only tested for antibodies against KLH.

2.3. ELISA. Polystyrene 96-well plates were coated with $100 \mu \mathrm{L} /$ well of a $20 \mu \mathrm{g} / \mathrm{mL}$ solution of either tetanus toxoid, KLH, or HEWL dissolved in PBS and then incubated overnight at $4^{\circ} \mathrm{C}$. Wells were washed three times for 3 minutes with $200 \mu \mathrm{L}$ per well of PBS-1\% BSA-0.05\% Tween buffer (PBS-T). Plasma samples from the immunization study were diluted $1: 25$ and $1: 100$. In order to compare measurements among plates, eight blood samples from unmanipulated turtles that were housed with the immunized turtles were run as references on every plate and then used to adjust values across plates. Plasma samples from 2007 and from hatchling plasma were diluted $1: 25$ in $100 \mu \mathrm{L}$ PBS-T in each well. For each antigen, all samples were run simultaneously on one plate. The plates were incubated at room temperature for 1 hour and then washed as before. One hundred microliters of 1:500 dilution of antiturtle light chain $\mathrm{mAb}$ conjugated to biotin (HL 673, University of Florida Hybridoma Facility) was added to each well and plates were incubated and washed as before. One hundred microliters of 1:1000 dilution of Streptavidin-HRP was added to each well and then incubated and washed as before. Plates were washed once with $100 \mu \mathrm{L} /$ well $\mathrm{ddH}_{2} \mathrm{o}$ before adding $100 \mu \mathrm{L} /$ well of ABTS powder dissolved in ABTS buffer solution (Southern Biotech). The optical density (OD) was determined using a Powerwave 340 plate reader (BioTech Inc.) with a $405 \mathrm{~nm}$ wavelength.

2.4. Avidity. Avidity was measured using a competitive ELISA [19]. Fifty microliters of test serum diluted in PBS (1:50) was added to six $50 \mu \mathrm{L}$ aliquots of antigen serially diluted in PBS-0.1\% BSA-0.05\% Tween $(0.08-5 \mathrm{mg} / \mathrm{mL})$ and two tubes of $50 \mu \mathrm{L}$ of PBS- $-0.1 \%$ BSA $-0.05 \%$ Tween only and incubated for $18 \mathrm{~h}$ at room temperature in glass tubes. An ELISA was then run as described above with the plates coated with the antigen of interest. Avidity values were calculated from the absorbance according to previously described methods [22]. Thus, for the individual turtle plasma sample, six values (one from each tube used in the serial dilution) were obtained by subtracting the absorbance

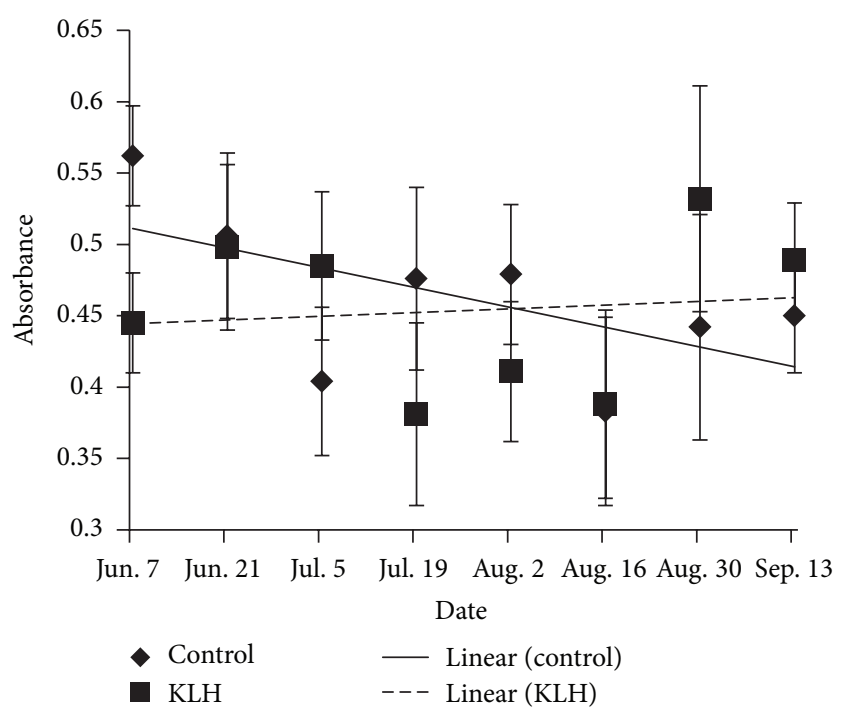

FIGURE 1: Least square mean $\mathrm{OD} \pm \mathrm{SE}$ for control turtles and turtles immunized with KLH at each sampling point.

in a well from the average absorbance of the wells that came from the tubes that contained no antigen. That number was divided by the molarity of the antigen present in the glass tube during incubation and those six values were then plotted. A linear regression was used and the slope of the line was the dissociation constant and avidity was then recorded as the reciprocal of the dissociation constant.

2.5. Statistics. A repeated measures analysis of covariance (RMANCOVA) was used to test for the effects of sampling point and immunization on antibody titers with plastron length as the covariate.

Antibody levels against HEWL were square root transformed prior to the analysis to meet the assumption of normality. A multivariate analysis of covariance (MANCOVA) was used to compare NAb levels between sexes and the different sampling dates with plastron length as the covariate. All interactions were tested and nonsignificant effects were removed from the model. Pearson correlation coefficients were calculated between NAb levels against each antigen.

\section{Results}

All adult animals tested demonstrated significant levels of $\mathrm{KLH}$ binding antibodies, even in the absence of immunization, and these did not vary over the course of the experiment $\left(F_{7,16}=0.38, P=0.88\right.$; Figure 1$)$. Despite repeated immunization, the amount of KLH-specific antibodies in immunized turtles did not differ from control turtles $\left(F_{7,7}=\right.$ $2.00, P=0.19)$. The date by plastron length interaction was not significant $\left(F_{7,7}=0.44, P=0.85\right)$.

Avidity did not vary over the course of the experiment $\left(F_{2,12}=0.26, P=0.77\right.$; Figure 2$)$ nor did it differ between immunized and control turtles over the course of the experiment $\left(F_{2,12}=01.24, P=0.32\right)$. The date by plastron length interaction was not significant $\left(F_{2,12}=0.21, P=0.81\right)$. 


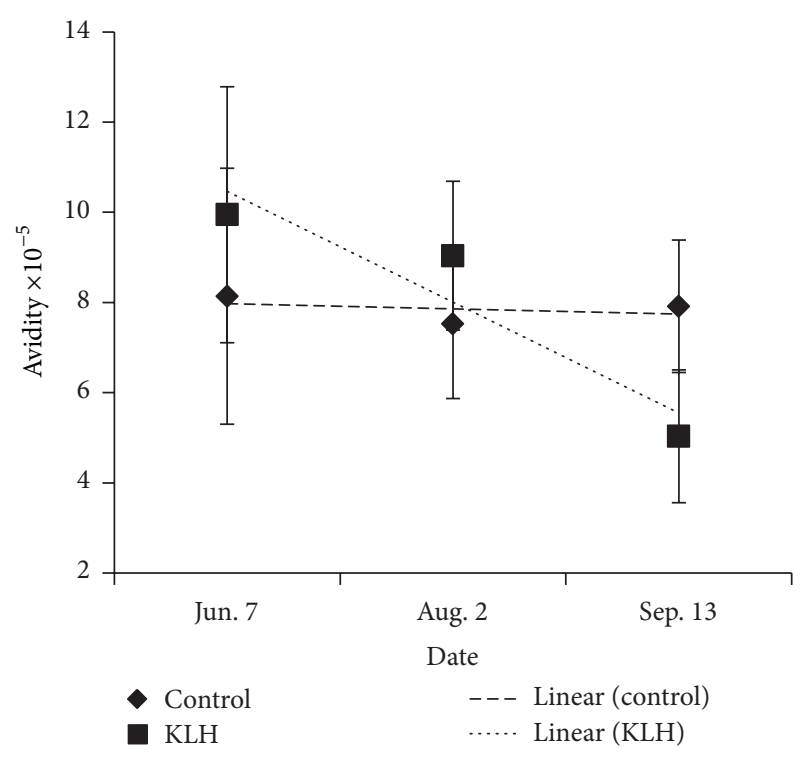

FIGURE 2: Least square mean avidity $\times 10^{-5} \pm$ SE for control turtles and turtles immunized with KLH before immunization, 8 weeks after the primary immunization and 6 weeks after the booster injection.

For the MANCOVA, the main effect of plastron length was significant, with larger turtles having higher amounts of NAbs against all antigens $\left(F_{3,30}=5.53, P=0.004\right.$; Figure 3$)$. Sampling date $\left(F_{15,96}=1.36, P=0.18\right)$ and $\operatorname{sex}\left(F_{3,30}=0.04\right.$, $P=0.99$ ) were not significant. Levels for all three antibodies were significantly and positively related with plastron length (KLH: $F_{1,40}=6.68, P=0.0137$, Figure 3(a); HEWL: $F_{1,40}=$ 12.13, $P \stackrel{\text {, }}{=} 0.0013$, Figure 3(b); Tetanus: $F_{1,40}=6.60, P=$ 0.0142 , Figure $3(\mathrm{c}))$. Antibody levels for all antigens were significantly correlated and positive (Table 1). Individuals that exhibited a stronger antigenic response to KLH also had stronger responses to both HEWL and tetanus toxoid. In contrast to adults, hatchling plasma did not have detectable levels of natural antibodies to KLH.

\section{Discussion}

To study humoral responses of red-eared slider turtles, we immunized individuals with a presumably novel antigen, KLH. However, upon testing, we discovered that most adult individuals had significant titers of preexisting KLH binding antibodies. Interestingly, turtles immunized with KLH did not produce increases in antibody titer over a 14-week period, even after secondary immunization. Other studies in reptiles have found that increased antibody titers can be detected around 1 to 4 weeks after immunization [22-25], even though peak antibody titers are not reached until anywhere from 6 to 9 weeks $[8,23-27]$. However, the latent period is shortened upon secondary immunization [27-29]. Therefore, our protocol should have been sufficient to detect an increase in antibody titers if the turtles were to produce one.

The high preimmunization titers and lack of response to immunization suggest that we are measuring a NAb response in the sliders. We detected antibodies to a series of antigens that the turtles should not have been exposed to previously (e.g., KLH, tetanus, and HEWL) and the avidities to KLH we report in this study $\left(10^{-5}\right.$ to $\left.10^{-6}\right)$ are within the range of the avidity for natural antibodies $\left(10^{-3}\right.$ to $\left.10^{-7}\right)$, even after immunization [11]. Reagents are not currently available to distinguish turtle antibody isotypes, but we would predict that these natural antibodies are of the IgM isotype.

Some studies in reptiles that report an increase in antibody titers after immunization have not detected antigen binding antibodies before the primary injection [24, 27]. However, it has been shown that water pythons have antibodies to diphtheria and tetanus prior to immunization and fail to increase antibody titers in response to both primary and secondary immunizations with these antigens [30]. In addition, immunization of desert tortoises with ovalbumin (OVA) resulted in a tradeoff between the production of NAbs and acquired antibodies against OVA [31].

So how do natural antibodies prevent B cells from producing antigen-specific antibodies in response to immunization? It has previously been hypothesized that NAbs occur at high enough titers to mask epitopes on the antigens and therefore prevent any further humoral response [3032]. The lack of change in avidity reported in the present study lends further support to this idea. In order for antibody production to occur, the antigen must be captured by the antigen-specific $B$ cell by binding to an Ig on the surface of the $B$ cell with a high enough affinity to activate the B cell to produce antibodies [33]. This activation then results in the $B$ cell producing an antibody with a higher affinity than NAbs that are produced in the absence of antigen stimulation [34]. Thus, the conservation of avidity to KLH throughout the immunization period suggests that the NAbs are masking the epitopes and not allowing the B cell to be activated. Previously, we found that B cells from sliders are able to respond in vitro to the stimulation with LPS by increasing both the number of antibody secreting cells and the amount of antibody secreted by each cell [19]. In this study, the B cells were isolated from whole blood, a process that removes any NAbs. Thus, when LPS was added to the culture media, there were no NAbs blocking the activation of the B cells, further supporting the epitope masking hypothesis.

Natural antibody levels to all antigens tested were positively correlated with size and presumably age. An ageassociated increase in NAbs has been shown in a number of taxa including fish [35], birds [36], reptiles [30], and mammals [37]. NAbs are produced by B-1 cells, which are long-lived and self-replenishing [38], and as the animal ages, $B$ cells are selected which react to environmental antigens [39] presumably causing an increase in NAb levels with time. This idea is further supported by our failure to detect natural antibodies in hatchling plasma. We have previously detected antibodies against KLH in yolk, presumably of maternal origin, and the levels of these antibodies decreased during development (unpublished data, LMZ). In addition, we have determined that hatchling plasma contains roughly four times lower levels of total immunoglobulins compared to adult plasma [18, 40]. Therefore, we believe it is likely that hatchlings do contain antibodies that can bind to 


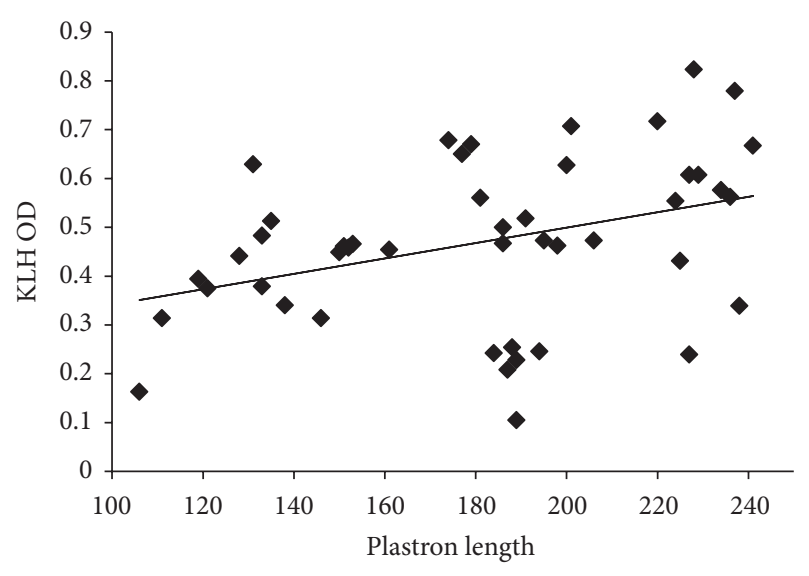

(a)

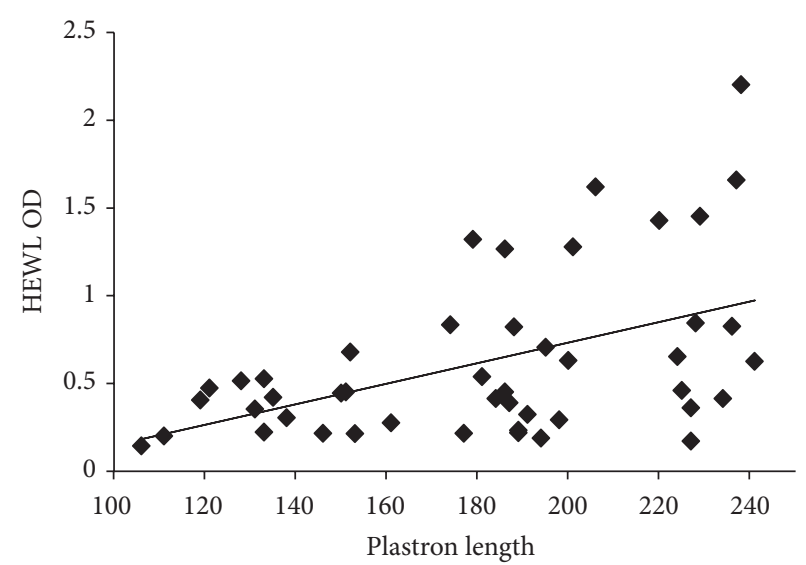

(b)

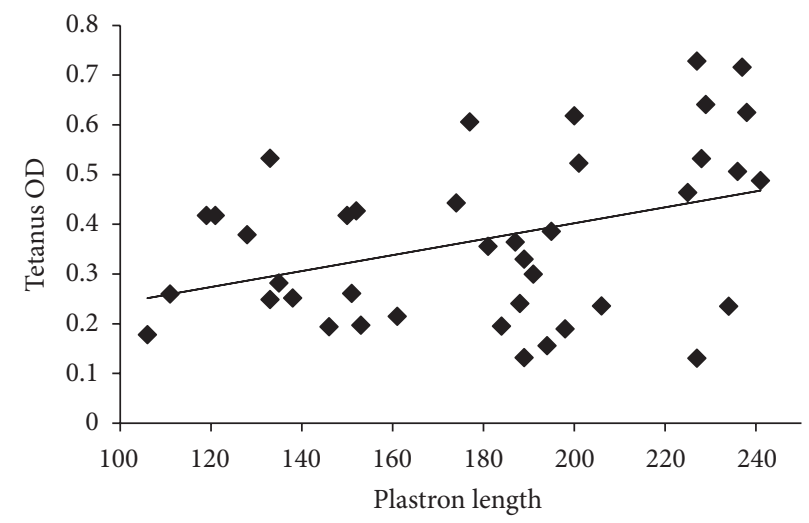

(c)

FIgURE 3: Relationship between plastron length and OD for (a) KLH, (b) HEWL, and (c) tetanus.

TABLE 1: Pearson correlation coefficients between OD for each antigen.

\begin{tabular}{lccc}
\hline & KLH & Tetanus & HEWL \\
\hline \multirow{2}{*}{ KLH } & & 0.64881 & 0.49888 \\
& & $P<0.0001$ & $P=0.0004$ \\
Tetanus & 0.64881 & & 0.59389 \\
& $P<0.0001$ & & $P<0.0001$ \\
HEWL & 0.49888 & 0.59389 & \\
& $P=0.0004$ & $P<0.0001$ & \\
\hline
\end{tabular}

$\mathrm{KLH}$, and the amount would increase with time, but at the stage of hatchling development used in the present study, the antibodies are present at levels below the threshold of detection by our assay. A similar result has been found in chickens, where newly hatched chicks had maternally derived IgY but did not produce antibodies against KLH until 5 to 7 weeks of age when all isotypes of antibodies began to be produced [41].

We did not detect a sex difference in NAb levels from plasma taken from turtles across the active season. Sex differences are a common finding in humoral immune measures in a variety of taxa, with females often exhibiting higher levels of immune responses [42]. However, in other studies on the same population of turtles, we have detected very little evidence for sex differences in a number of humoral immune measures, including total immunoglobulin levels, the number of antibody secreting cells, and the amount of LPS-specific antibodies $[18,19]$.

We also found no effect of date on NAb levels. In previous studies, we found a buildup of total immunoglobulin levels and levels of LPS-specific antibodies across the active season, suggesting an accumulation of pathogen exposures [18, 19]. However, we also found no seasonal changes in the ability of cells to produce antibodies either spontaneously or in response to stimulation [19].

While monoclonal NAbs have been identified, most are polyreactive to structurally unrelated antigens [43]. Antibody levels to all three antigens tested here were positively correlated to each other, and it is unclear if a single antibody is able to bind to all three antigens or if there are separate antibodies binding to each antigen. Madsen et al. [30] report a similar result, finding that water pythons with high levels of NAbs to tetanus also have high levels to diphtheria. Polyreactive antibodies have been shown to be more effective when compared to monoreactive antibodies in activating the innate immune system by inhibiting bacterial growth, enhancing phagocytosis, and triggering complement [43]. 
Thus, polyreactive antibodies with low binding affinities, as part of a quickly responding innate immune system, may be advantageous for a reptile instead of relying on a humoral response that might not peak until 6 or more weeks after contact with a pathogen.

Other studies in reptiles have shown that aspects of innate immunity can be stronger and of much broader range than their mammalian counterparts. For example, several types of antimicrobial peptides have been found in reptiles, and one isolated from snake venom from the branded krait, Bungarus fasciatus, was found to be a more potent antibiotic than ampicillin and benzylpenicillin and even demonstrated antimicrobial activity against several strains of clinically isolated drugresistant Salmonella typhi and Klebsiella pneumoniae [44]. Serum from American alligator (Alligator mississippiensis) was shown to have broad range antibacterial activity against both gram-negative and gram-positive bacteria, including several strains which human serum was not effective against [45]. NAbs play an important part of this strong innate immunity by triggering complement, neutralizing bacteria directly through lysis, and enhancing phagocytosis [11]. Reptiles may use NAbs along with other innate components to form a quickly responding nonspecific first line of defense instead of relying on a much slower specific humoral response.

\section{Conclusions}

In this study, we immunized turtles with a presumably novel antigen, KLH. While the turtles did not mount an increase in antibody titers with immunization, preimmunization titers to $\mathrm{KLH}$ and a number of other antigens were high, suggesting a NAb response. Antibody titers also increased with age. NAbs may be especially important for reptiles because of their slow adaptive immune response, and thus NAbs may form a central component of a robust innate immune response in red-eared sliders.

\section{Acknowledgments}

The authors would like to thank Steve Juliano for statistical advice and Ryan Paitz for the help with fieldwork. They would also like to thank the Illinois Department of Natural Resources for allowing access to Banner Marsh. This research was supported by National Science Foundation Grant IOS00748505 to Rachel M. Bowden and Laura A. Vogel, a College of Arts \& Sciences University Research Grant to Rachel M. Bowden, and a Phi Sigma Beta Lambda chapter Weigel Grant to Laura M. Zimmerman.

\section{References}

[1] R. Medzhitov and C. Janeway Jr., "Innate immunity," The New England Journal of Medicine, vol. 343, no. 5, pp. 338-344, 2000.

[2] H. B. Oral, C. Özakin, and C. A. Akdiş, "Back to the future: antibody-based strategies for the treatment of infectious diseases," Molecular Biotechnology, vol. 21, no. 3, pp. 225-239, 2002.

[3] T. Snoeijs, M. Eens, E. van den Steen, and R. Pinxten, "Kinetics of primary antibody responses to sheep red blood cells in birds: a literature review and new data from great tits and European starlings," Animal Biology, vol. 57, no. 1, pp. 79-95, 2007.

[4] R. D. Jurd, "Reptiles and birds," in Immunology: A Comparative Approach, R. J. Turner, Ed., pp.137-172, John Wiley \& Sons, West Sussex, UK, 1994.

[5] M. Or-Guil, N. Wittenbrink, A. A. Weiser, and J. Schuchhardt, "Recirculation of germinal center B cells: a multilevel selection strategy for antibody maturation," Immunological Reviews, vol. 216, no. 1, pp. 130-141, 2007.

[6] F. Davison, B. Kaspers, and K. A. Schat, Avian Immunology, Elsevier/Academic Press, Boston, Mass, USA, 2008.

[7] L. M. Zimmerman, L. A. Vogel, and R. M. Bowden, "Understanding the vertebrate immune system: insights from the reptilian perspective," Journal of Experimental Biology, vol. 213, no. 5, pp. 661-671, 2010.

[8] H. M. Grey, "Phylogeny of the immune response: studies on some physical, chemical, and serologic characteristics of antibody produced in the turtle," Journal of Immunology, vol. 91, no. 6, pp. 819-825, 1963.

[9] B. M. Longenecker and T. R. Mosmann, “Natural' antibodies to chicken MHC antigens are present in mice, rats, humans, alligators and allogeneic chickens," Immunogenetics, vol. 11, no. 3, pp. 293-302, 1980.

[10] R. Gonzalez, J. Charlemagne, W. Mahana, and S. Avrameas, "Specificity of natural serum antibodies present in phylogenetically distinct fish species," Immunology, vol. 63, no. 1, pp. 31-36, 1988.

[11] A. F. Ochsenbein and R. M. Zinkernagel, "Natural antibodies and complement link innate and acquired immunity," Immunology Today, vol. 21, no. 12, pp. 624-630, 2000.

[12] Y. Naparstek, J. Andre-Schwartz, T. Manser et al., "A single germline $V_{H}$ gene segment of normal $A / J$ mice encodes autoantibodies characteristic of systemic lupus erythematosus," Journal of Experimental Medicine, vol. 164, no. 2, pp. 614-626, 1986.

[13] S. Avrameas, "Natural autoantibodies: from "horror autotoxicus" to 'gnothi seauton"' Immunology Today, vol. 12, pp. 154-159, 1991.

[14] C. J. Binder, M.-Y. Chou, L. Fogelstrand et al., "Natural antibodies in murine atherosclerosis," Current Drug Targets, vol. 9, no. 3, pp. 190-195, 2008.

[15] M. Boes, A. P. Prodeus, T. Schmidt, M. C. Carroll, and J. Chen, "A critical role of natural immunoglobulin $\mathrm{M}$ in immediate defense against systemic bacterial infection," Journal of Experimental Medicine, vol. 188, no. 12, pp. 2381-2386, 1998.

[16] A. F. Ochsenbein, T. Fehr, C. Lutz et al., "Control of early viral and bacterial distribution and disease by natural antibodies," Science, vol. 286, no. 5447, pp. 2156-2159, 1999.

[17] C. H. Ernst, J. E. Lovich, and R. W. Barbour, Turtles of the United States and Canada, Smithsonian Institution Press, Washington, DC, USA, 1994.

[18] L. M. Zimmerman, R. T. Paitz, L. A. Vogel, and R. M. Bowden, "Variation in the seasonal patterns of innate and adaptive immunity in the red-eared slider (Trachemys scripta)," Journal of Experimental Biology, vol. 213, no. 9, pp. 1477-1483, 2010.

[19] L. M. Zimmerman, S. G. Clairardin, R. T. Paitz et al., "Humoral immune responses are maintained with age in a long-lived ectotherm, the red-eared slider turtle," Journal of Experimental Biology, vol. 216, pp. 633-640, 2013.

[20] H. M. Wilbur, "A growth model for the turtle Chrysemys picta," Copeia, no. 2, pp. 337-343, 1975. 
[21] J. W. Gibbons, R. D. Semlitsch, J. L. Greene, and J. P. Schubauer, "Variation in age and size at maturity of the slider turtle (Pseudemys scripta)," The American Naturalist, vol. 117, no. 5, pp. 841$845,1981$.

[22] B. Friguet, A. F. Chaffotte, L. Djavadi-Ohaniance, and M. E. Goldberg, "Measurements of the true affinity constant in solution of antigen-antibody complexes by enzyme-linked immunosorbent assay," Journal of Immunological Methods, vol. 77, no. 2, pp. 305-319, 1985.

[23] G. A. Ingram and D. H. Molyneux, "The primary humoral immune response of European green lizards (Lacerta viridis) to Leishmania agamae," Parasite Immunology, vol. 5, no. 1, pp. 95108, 1983.

[24] G. W. Pye, D. R. Brown, M. F. Nogueira et al., "Experimental inoculation of broad-nosed caimans (Caiman latirostris) and Siamese crocodiles (Crocodylus siamensis) with Mycoplasma alligatoris," Journal of Zoo and Wildlife Medicine, vol. 32, no. 2, pp. 196-201, 2001.

[25] F. C. Origgi, P. A. Klein, K. Mathes et al., "Enzyme-linked immunosorbent assay for detecting herpesvirus exposure in Mediterranean tortoises (spur-thighed tortoise [Testudo graeca] and Hermann's tortoise [Testudo hermanni])," Journal of Clinical Microbiology, vol. 39, no. 9, pp. 3156-3163, 2001.

[26] J. J. Marchalonis, E. H. Ealey, and E. Diener, "Immune response of the Tuatara, Sphenodon punctatum," The Australian Journal of Experimental Biology and Medical Science, vol. 47, no. 3, pp. 367-380, 1969.

[27] T. M. Work, G. H. Balazs, R. A. Rameyer, S. P. Chang, and J. Berestecky, "Assessing humoral and cell-mediated immune response in Hawaiian green turtles, Chelonia mydas," Veterinary Immunology and Immunopathology, vol. 74, no. 3-4, pp. 179-194, 2000.

[28] P. Kanakambika and V. Muthukkaruppan, "The immune response to sheep erythrocytes in the lizard Calotes versicolor," Journal of Immunology, vol. 109, no. 3, pp. 415-419, 1972.

[29] B. Ujvari and T. Madsen, "Age, parasites, and condition affect humoral immune response in tropical pythons," Behavioral Ecology, vol. 17, no. 1, pp. 20-24, 2006.

[30] T. Madsen, B. Ujvari, K. S. Nandakumar, D. Hasselquist, and R. Holmdahl, "Do "infectious" prey select for high levels of natural antibodies in tropical pythons?" Evolutionary Ecology, vol. 21, no. 2, pp. 271-279, 2007.

[31] F. C. Sandmeier, C. R. Tracy, S. Dupre, and K. Hunter, "A tradeoff between natural and acquired antibody production in a reptile: implications for long-term resistance to disease," Biology Open, vol. 1, no. 11, pp. 1078-1082, 2012.

[32] B. Heyman, "Regulation of antibody responses via antibodies, complement, and Fc receptors," Annual Review of Immunology, vol. 18, pp. 709-737, 2000.

[33] R. Brink, T. G. Phan, D. Paus, and T. D. Chan, "Visualizing the effects of antigen affinity on T-dependent B-cell differentiation," Immunology and Cell Biology, vol. 86, no. 1, pp. 31-39, 2008.

[34] U. Bruderer, S. J. Cryz Jr., U. B. Schaad, M. Deusinger, J. U. Que, and A. B. Lang, "Affinity constants of naturally acquired and vaccine-induced anti-Pseudomonas aeruginosa antibodies in healthy adults and cystic fibrosis patients," Journal of Infectious Diseases, vol. 166, no. 2, pp. 344-349, 1992.

[35] N. M. Kachamakova, I. Irnazarow, H. K. Parmentier, H. F. J. Savelkoul, A. Pilarczyk, and G. F. Wiegertjes, "Genetic differences in natural antibody levels in common carp (Cyprinus carpio L.)," Fish and Shellfish Immunology, vol. 21, no. 4, pp. 404413, 2006.
[36] H. K. Parmentier, A. Lammers, J. J. Hoekman, G. de Vries Reilingh, I. T. A. Zaanen, and H. F. J. Savelkoul, "Different levels of natural antibodies in chickens divergently selected for specific antibody responses," Developmental and Comparative Immunology, vol. 28, no. 1, pp. 39-49, 2004.

[37] L. Benatuil, J. Kaye, N. Cretin et al., "Ig knock-in mice producing anti-carbohydrate antibodies: breakthrough of B cells producing low affinity anti-self antibodies," Journal of Immunology, vol. 180 , no. 6, pp. 3839-3848, 2008.

[38] N. Baumgarth, J. W. Tung, and L. A. Herzenberg, "Inherent specificities in natural antibodies: a key to immune defense against pathogen invasion," Springer Seminars in Immunopathology, vol. 26, no. 4, pp. 347-362, 2005.

[39] S. A. Johnson, S. J. Rozzo, and J. C. Cambier, "Aging-dependent exclusion of antigen-inexperienced cells from the peripheral B cell repertoire," Journal of Immunology, vol. 168, no. 10, pp. 50145023,2002

[40] L. M. Zimmerman, R. T. Paitz, S. G. Clairardin, L. A. Vogel, and R. M. Bowden, "No evidence that estrogens affect the development of the immune system in the red-eared slider turtle, Trachemys scripta," Hormones and Behavior, vol. 62, no. 3, pp. 331-336, 2012.

[41] T. Koppenheffer, "Ontogeny of antibody production against microbial cell wall constituents in juvenile chickens," The FASEB Journal, vol. 22, p. 560, 2008.

[42] S. L. Klein, "Hormones and mating system affect sex and species differences in immune function among vertebrates," Behavioural Processes, vol. 51, no. 1-3, pp. 149-166, 2000.

[43] Z.-H. Zhou, A. G. Tzioufas, and A. L. Notkins, "Properties and function of polyreactive antibodies and polyreactive antigenbinding B cells," Journal of Autoimmunity, vol. 29, no. 4, pp. 219$228,2007$.

[44] Y. Wang, J. Hong, X. Liu et al., "Snake cathelicidin from Bungarus fasciatus is a potent peptide antibiotics," PLoS ONE, vol. 3, no. 9, Article ID e3217, 2008.

[45] M. E. Merchant, C. Roche, R. M. Elsey, and J. Prudhomme, "Antibacterial properties of serum from the American alligator (Alligator mississippiensis)," Comparative Biochemistry and Physiology B, vol. 136, no. 3, pp. 505-513, 2003. 

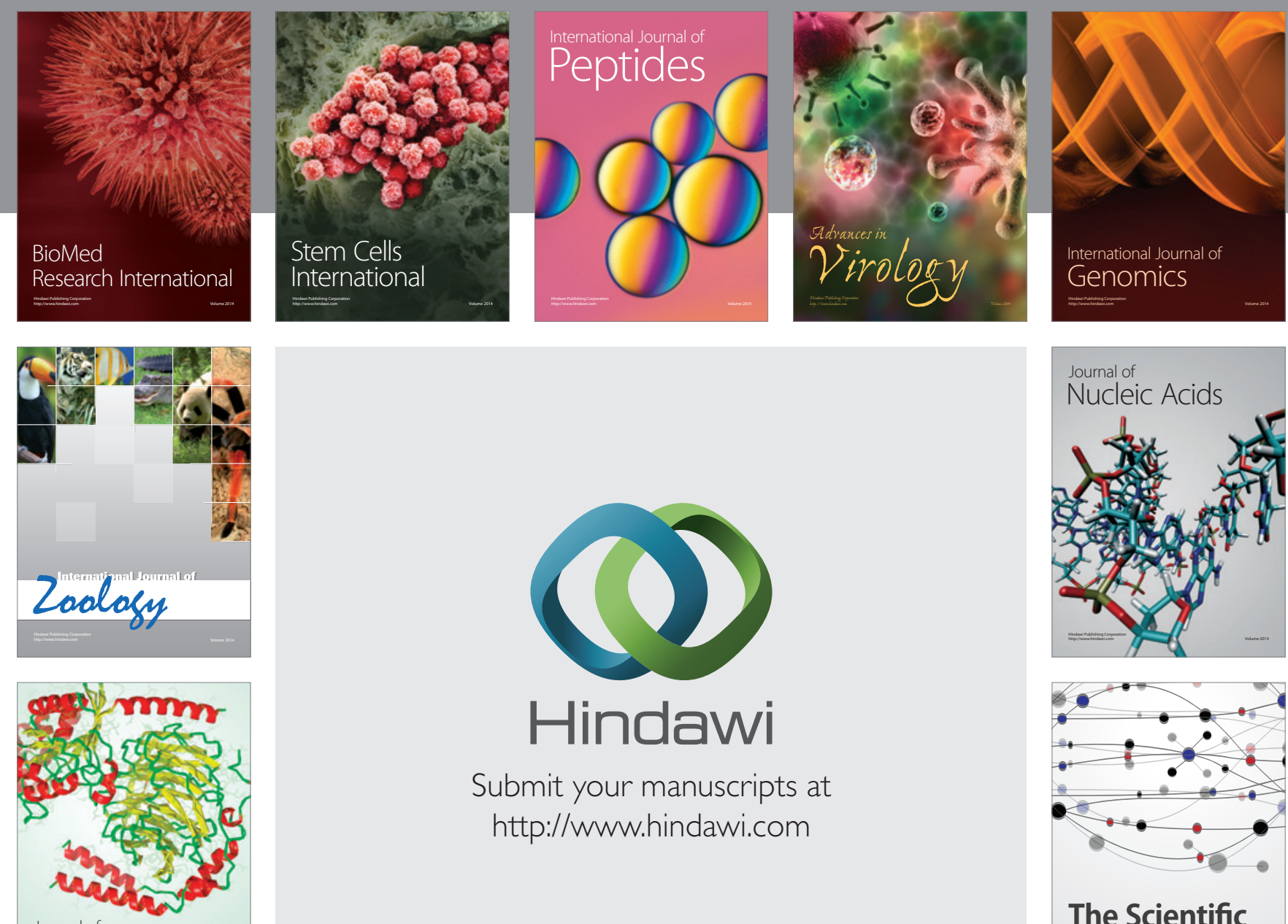

Submit your manuscripts at

http://www.hindawi.com

Journal of
Signal Transduction
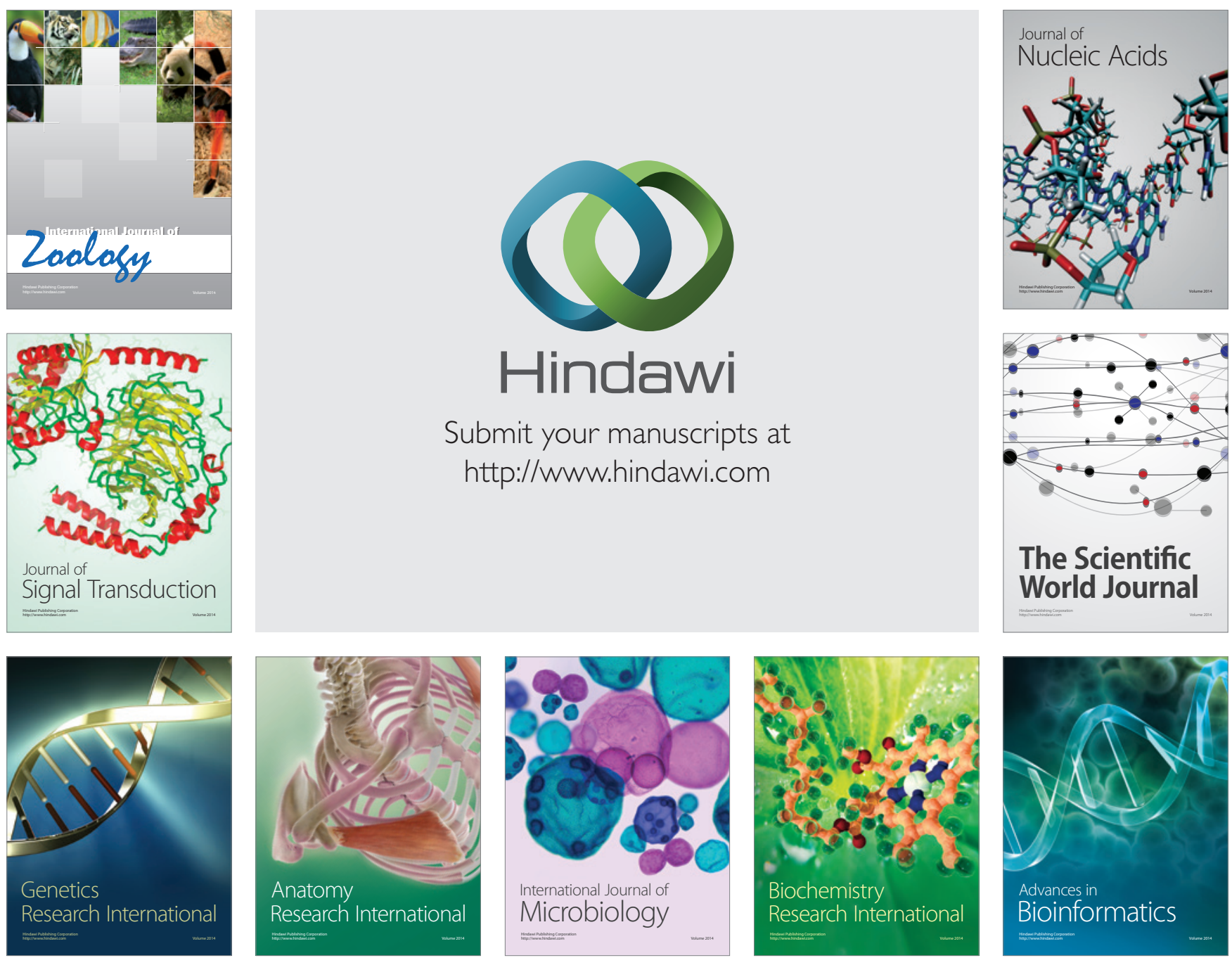

The Scientific World Journal
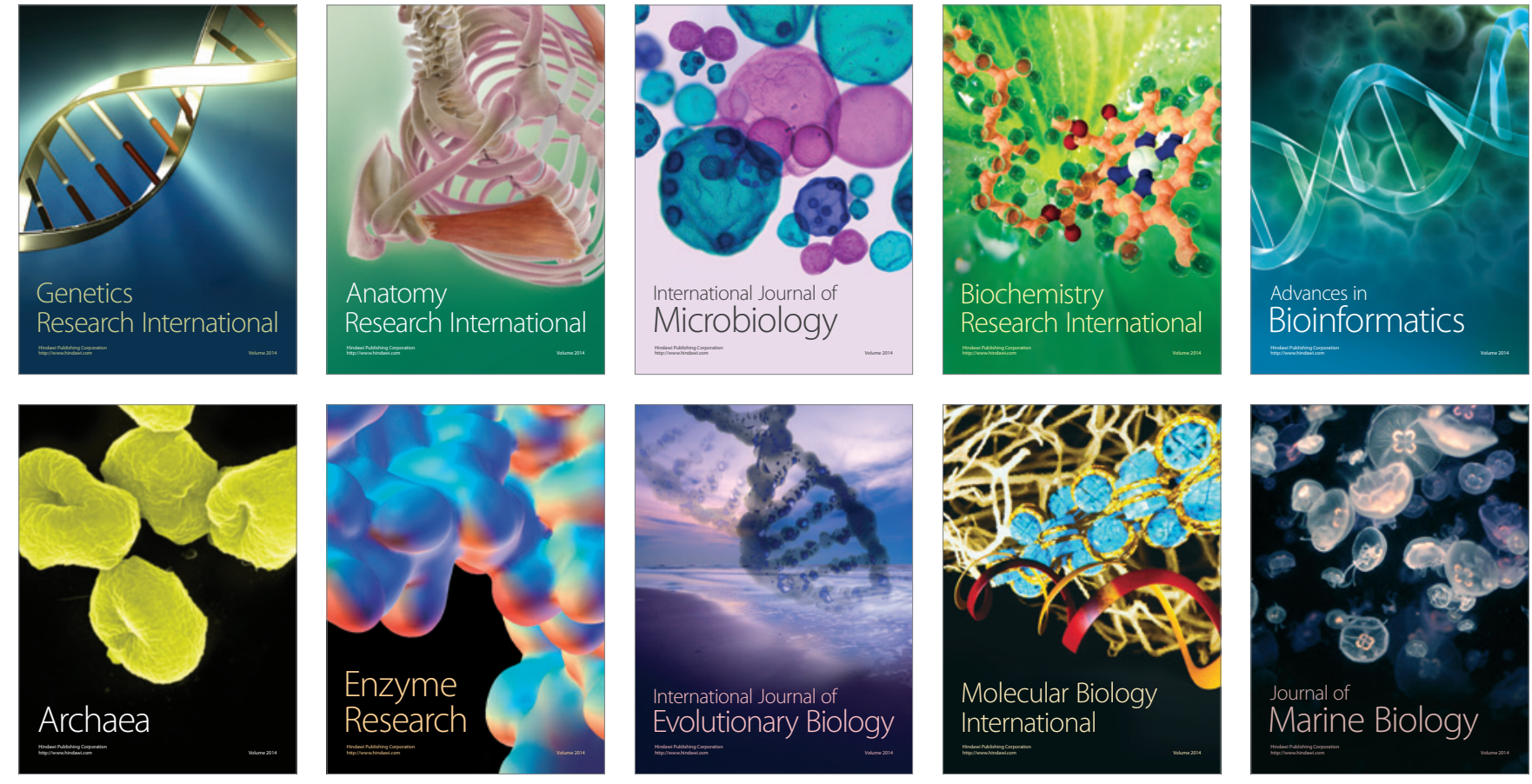